Published in final edited form as:

Res Q Exerc Sport. 2008 December ; 79(4): 458-467.

\title{
Sedentary Activity and Body Composition of Middle School Girls: The Trial of Activity for Adolescent Girls
}

\author{
Charlotte Pratt, \\ National Heart, Lung, and Blood Institute, Bethesda, MD \\ Larry S. Webber, \\ Biostatistics Department at Tulane University \\ Chris D. Baggett, \\ School of Public Health at the University of North Carolina-Chapel Hill \\ Dianne Ward, \\ School of Public Health at the University of North Carolina-Chapel Hill \\ Russell R. Pate, \\ Department of Exercise Science at the University of South Carolina \\ David Murray, \\ College of Public Health at The Ohio State University \\ Timothy Lohman, \\ Department of Physiology at the University of Arizona \\ Leslie Lytle, and \\ School of Public Health at the University of Minnesota \\ John P. Elder \\ School of Public Health at San Diego State University
}

\begin{abstract}
This study describes the relationships between sedentary activity and body composition in 1,458 sixth-grade girls from 36 middle schools across the United States. Multivariate associations between sedentary activity and body composition were examined with regression analyses using general linear mixed models. Mean age, body mass index, and percentage of body fat were $12.0 \pm 0.51,21.1 \mathrm{~kg} /$ $\mathrm{m}^{2} \pm 4.8,28.5 \pm 8.9$, respectively. Girls averaged $7.7 \pm 1.2$ sedentary hours per day and about $13 \mathrm{hr}$ $(\sim 97 \%$ of the day) of both sedentary and light activities. Overweight girls were significantly more (13 min; $\mathrm{p}<.003)$ sedentary, especially after school (> 2 p.m.; $\mathrm{p}<.01)$, and less physically active $(\mathrm{p}<.0001)$ than normal weight girls. The study documents small but significant associations between sedentary activity and adiposity.
\end{abstract}

\section{Keywords}

accelerometry; body fat; body mass index; sedentary behavior

@2008 by the American Alliance for Health, Physical Education, Recreation and Dance

E-mail: E-mail: prattc@nhlbi.nih.gov. 
Childhood obesity has increased dramatically over the past decades and continues to be a national public health problem (Ogden et al., 2006). Simultaneously, obesity-related diseases such as type 2 diabetes and hypertension have increased in the pediatric population (Daniels et al., 2005) These increases are partly attributed to a decline in physical activity and an increase in sedentary behavior, particularly among adolescents (Kimm et al, 2002; Nelson, LarsenGordon, Adair, \& Popkin, 2005). The emergence of electronic media, including computer and video games, internet, and cellular phones has paralleled the increase in childhood obesity and may have contributed to the concomitant increase in sedentary behavior, particularly among adolescents (Pratt, Macera, \& Blanton, 1999). Sedentary behaviors have been defined as activities of low intensity (Must \& Tybor, 2005). Among the of activity types, television viewing and video game use are the most studied (Must \& Tybor, 2005). Other less well studied behaviors include talking with friends on the phone, sitting, and napping.

Robinson (2001) identified three potential mechanisms that could link television viewing and obesity: (a) reduced energy expenditure from television (TV) viewing displaced physical activity, (b) increased intake of energy-dense foods brought about by food advertising, and (c) reduced energy metabolism. In a randomized controlled trial, reduction in TV viewing attenuated the age-related increase in body fatness (Robinson, 1999). In a meta-analysis of 52 studies, Marshall, Biddle, Gorely, Cameron, and Murdey (2004) found a statistically significant relationship between TV viewing and body fat, although the relationship was not clinically significant. Most of the significant relationships between sedentary behavior (usually TV viewing) and adiposity were with children younger than 10 years of age (Must \& Tybor, 2005; Marshall et al., 2004).

Inconsistent relationships between sedentary behavior and obesity have been reported in studies of children 12 years or older. Self-reports of hours of weekly TV watching, video use, and computer use were unrelated to body mass index (BMI) 4 years later in 335 12-year-old Welsh children (Elgar, Roberts, \& Tudor-Smith, 2005). Similarly, in the United States, there was no relationship between TV viewing and change in BMI or body fat in 12-year-olds followed for 2 years (Robinson et al., 1993). Similar null findings have been reported in other studies (Kettaneh et al., 2005; Maffeis, Talamini, \& Tato, 1998). In contrast, two prospective observational studies found significant associations between sedentary behavior and adiposity (Gordon-Larsen, Melissa, \& Popkin, 2004; Gortmaker et al., 1996). In one, more than 35 hr/ week of TV and video game use increased the odds of becoming obese by $49 \%$ in boys and $43 \%$ in girls ages 12-22 years (Gordon-Larsen et al., 2004). In the other, TV viewing by 10 15-year-olds was a significant predictor of overweight 4 years later (Gortmaker et al., 1996). Similar positive relationships have been reported among sedentary behavior (TV/video and computer use), BMI, and unhealthful dietary behaviors in cross-sectional studies of middle and high school students (Utter, Sztainer-Neumark, Jeffery, \& Story, 2003; Lowry et al., 2002).

This study examined the relationships between the time spent in sedentary activities and both body fat and BMI in adolescent girls participating in the Trial of Activity for Adolescent Girls (TAAG), with time spent in sedentary activity measured by accelerometers. Self-report measures of sedentary behavior were also collected using the Three-Day Physical Activity Recall (3DPAR). To our knowledge, the relationship between times spent in sedentary activities and body composition, assessed objectively and by self-report in middle school girls, has not been critically evaluated.

\section{Method}

\section{Study Design}

The TAAG is a multicenter field study of 36 middle schools designed to determine if a schooland community-based intervention reduces the age-related decline in middle school girls' 
moderate-to-vigorous physical activity. Participating institutions include Universities of Arizona, Maryland, Minnesota, South Carolina, San Diego State, and Tulane. The University of North Carolina-Chapel Hill and the Project Office of the National Heart, Lung, and Blood Institute coordinated the study. The details of the study design have been reported elsewhere (Stevens et al., 2005). This paper reports on baseline data from a cross-sectional U.S. sample.

\section{Participants}

Sixth-grade girls, 12 years old, from 36 middle schools located in and around six geographic field centers in Tucson, AZ, Baltimore, MD, Minneapolis, MN, San Diego, CA, New Orleans, LA, and Columbia, SC, were recruited to participate in the study. Schools were eligible to participate if they had 90 or more girls, drop-out rates of no more than $35 \%$, and offered physical education classes from sixth through eighth grade. Eligible schools signed memoranda of understanding agreeing to be assigned randomly to intervention or control conditions. A random cross-sectional sample of 60 sixth-grade girls was selected for baseline measurement from each school. Girls were eligible for measurement if they gave assent and had parental consent, could read and understand English, and had not been told by their physician that they could not participate in physical activity. Eighty percent $(N=1,721)$ of the sample assented and had parental consent. However, 64 girls had incomplete or missing 3DPAR data, 108 had incomplete or missing data, 27 had no BMI or body fat measures, 45 were below the 5th percentile for BMI, and 19 were missing data related to participation in free or low-cost school lunches. Therefore, 1,458 (84.7\%) girls had complete data for statistical analyses for this paper. Girls with missing data were not different in racial/ethnic characteristics, percent receiving reduced- or free-school lunch, or the percentage of normal weight, at-risk-of-overweight, or overweight. Each participating institution's Human Subjects Review Board approved the study.

\section{Measurements}

This study used baseline data from anthropometric measures and student questionnaires. Measurement coordinators and staff from each field site were trained and certified.

Sociodemographic Characteristics-Sixth-grade girls completed questionnaires on their age, race/ethnicity, and participation in reduced or free school lunches. Race/ethnicity included Caucasian (White, non-Hispanic), Black or African American, Hispanic, Asian, Native Hawaiian/Pacific Islander, American Indian/Alaskan Native, and Other (e.g., multiracial). They responded yes, no, or don't know to the question, "Do you get free or lowcost lunches at school?" On a 5-point Likert-type scale (agree a lot, agree a little, neither agree nor disagree, disagree a little, or disagree a lot), they also responded to questions on difficulty in accessing facilities for physical activity.

Body Mass Index and Body Fat-Girls' weight and height were obtained using a standardized protocol. They were measured twice to the nearest $0.1 \mathrm{~kg}$ on an electronic scale (Model 770, Seca, Hamburg, Germany). Height was measured twice to the nearest $0.1 \mathrm{~cm}$ using a portable stadiometer (Shorr Height Measuring Board, Olney, MD). An average of two readings from each height and weight measurement was used in the analyses. Body mass index (BMI) was calculated as weight $(\mathrm{kg})$ divided by height in meters squared $\left(\mathrm{m}^{2}\right)$. Adolescents were classified as not overweight (5th to $<85$ th percentile of weight-for-height), at-risk of overweight $(\geq 85$ th to $<95$ th percentile of weight-for-height), or overweight $(\geq 95$ th percentile of weight-for-height) using Centers for Disease Control and Prevention (CDC) standards (Ogden et al., 2002). Triceps skinfolds were measured on the right side of the body or on the left, if girls had physical injuries or disabilities, and were recorded to the nearest millimeter. Percentage of body fat was calculated using the equation developed from preliminary studies of adolescent girls by TAAG investigators: 
Percent fat $=-23.393+2.269(\mathrm{BMI})+1.943$ (triceps skinfold $)-2.955($ Black $=1 ; 0$

$=$ Other) -0.524 (age) -0.058 (BMI*triceps skinfold)

In validation studies, the equation was shown to have $\mathrm{R}^{2}=.88$ for predicting percentage of body fat against the same measures obtained from dual energy X-ray absorptiometry (Lohman et al., 2006).

Accelerometry-Accelerometry (MTI ActiGraph, Model 7165; Manufacturing Technologies Inc. Health Systems, Shalimar, FL) was used to measure time spent in sedentary behavior. Prior to use in this study, accelerometers were examined at the University of North Carolina-Chapel Hill Coordinating Center for similarity of basic function using a standard laboratory shaker. The monitors were initialized to begin collecting data at 5:00 a.m. on the day after they were distributed and placed on a standard belt provided by the study investigators. Girls wore the accelerometers on their right hips except when sleeping, bathing, or swimming. Data for six complete days were available for analyses. School staff collected the accelerometers from the girls after 1 week. Data were uploaded from the monitors to a portable computer and transmitted to the coordinating center. Activity counts were accumulated over 30 -s intervals for 6 days. To help minimize the school-level intraclass correlations between girls within a school, data were collected over at least two separate calendar weeks in each participating school (Murray et al., 2004).

ActiGraph readings were processed using methods previously described (Treuth et al., 2004; Catellier et al., 2005). ActiGraph counts were reduced to time per day spent in sedentary pursuits using a cut point of $\leq 50$ counts/30 s ( 2.1 metabolic equivalents [METs]), based on preliminary specificity and sensitivity studies discriminating sedentary activities from light, moderate, and vigorous activities (Treuth et al., 2004). The count threshold for light activity was set at 51-1,499 counts/30 s ( $<4.6$ METs) and at 1,500 to $<2,600$ counts/30 s (4.6 METs) for moderate-to-vigorous physical activity. Half-minute counts were used instead of fullminute counts based on the expectation that they would be more sensitive to fluctuations in activity levels. Occasional missing data in a 6-day record were imputed using the Expectation Maximization algorithm (Catellier et al., 2005). We judged girls to be compliant with the protocol if they wore the monitor $80 \%$ of the time within a given day and blocks roughly corresponded to before school, during school, after school, early evening, and evening. If the girl was compliant for a block, we used the data provided; if not, we used imputation to fill in the missing data for that block, with at least one compliant day required for each girl. This resulted in at least $10.6 \mathrm{hr}$ of data on weekdays and $6.0 \mathrm{hr}$ on weekend days.

Physical Activity Recall-In addition to accelerometry, 3DPAR was used to assess physical activity participation by self-report. The 3DPAR has been validated in adolescent girls by comparison with MTI ActiGraph accelerometer counts $(r=.28-.46$; McMurray et al., 2004; Weston, Petosa, \& Pate, 1997). The 3DPAR form consists of three grids (one for each day) divided into 30-min segments, or blocks, to record the activities performed and their intensities. Girls indicated the "main activity" (by code number) performed during the time block and the subjective intensity rating. The codes corresponded to a list of 70 activities arranged in categories (eating, sleeping, personal care, transportation, work/school, spare time, play/recreation, and exercise/workout). For assessing intensity level, the 3DPAR used definitions and graphic figures to explain the intensity codes (light, moderate, hard, very hard). Each 30-min block of each day was assigned a MET intensity from the compendium (Ainsworth et al., 2000) to represent the main activity performed during the time period.

\section{Analyses}

Statistical analyses were conducted using SAS version 8.02 (SAS Institute, Cary, NC). Unadjusted means and frequencies of descriptive characteristics were calculated. Multivariate 
associations between sedentary activity and both BMI and percentage of body fat were examined with a regression analysis using the general linear mixed model. Separate models were used to test for group differences in mean levels of sedentary activity by BMI and body fat categories. In each model, race/ethnicity was treated as fixed effects along with BMI or percentage of body fat. The field center and school within the field center were included as random effects to account for the response correlation within schools and schools within field centers. To test for differences in sedentary activity by field center, field center and race/ ethnicity were treated as fixed effects, while school was included as a random effect. Adjusted means for field center, BMI, and percentage of body fat categories were estimated based on the observed marginal distribution of the covariates.

Mixed model analyses were also used to examine the association between body composition and race/ ethnicity. In separate models, BMI and body fat were modeled as continuous outcomes, while race/ethnicity was treated as a categorical fixed effect. Additionally, the associations between sedentary behavior/physical activity and race/ethnicity and receiving reduced or free lunch were examined. Race/ethnicity or reduced/free lunch was treated as the lone fixed effect. To ensure the associations between body composition and sedentary behavior were not confounded by differences in the number of hours monitored by accelerometry, we examined the effects of BMI and body fat on the number of hours participants wore the monitor. In each model, the field center and school within the field center were included as random effects.

\section{Results}

\section{Participation and Selected Characteristics}

Table 1 presents the sociodemographic characteristics of sixth-grade girls participating in TAAG. The mean age was $12.0 \pm 0.51$ years with a range of 10.6-14.6 years. The participants were ethnically diverse, with 44.1\% Caucasian, 22.0\% African American, 22.0\% Hispanic, and $11.9 \%$ other. The racial distributions of the study population were similar to those of their home states. About $42.2 \%$ of the participants received free or reduced school lunches.

Mean BMI was $21.1 \mathrm{~kg} / \mathrm{m}^{2}$ (range: $14.7-44.8 \mathrm{~kg} / \mathrm{m}^{2}$ ). About $35 \%$ of the girls exceeded the 85th percentile of BMI as determined by CDC standards and were considered overweight or at risk for overweight. Percentage of body fat ranged from $8.4 \%$ to $51.3 \%$, with almost $41 \%$ having $30 \%$ or more body fat. Significant racial/ethnic differences in BMI $(p<.01)$ and percentage of body fat $(p<.05)$ were observed, with African American and Hispanic girls having higher values than Caucasians.

Girls averaged 7.7 sedentary hours per day, which represented about $56 \%$ of the day. There was a wide range in the number of sedentary activity hours from as few as $3.5 \mathrm{hr}$ to as many as $11.6 \mathrm{hr}$. There were no differences in the distribution of sedentary hours by BMI or body fat, although the distribution is skewed to the right for normal weight girls (see Figure 1). Girls averaged $5.7 \mathrm{hr}$ per day of light activity, representing an additional $41.4 \%$ of the day. Thus, the girls spent about $13 \mathrm{hr}(\sim 97 \%)$ of the day in sedentary and light activities. There were no significant racial/ethnic differences in the number of sedentary or light activity hours when measured by accelerometers. Girls who participated in reduced or free school lunches did not differ significantly in the number of sedentary or light activity hours than those who did not.

Based on the 3DPAR, there was a daily average of thirty-two 30-min blocks of sedentary and light activity (<3.0 METS); while accruing a little more than two 30-min blocks of activity between 3.0 and 4.6 METS. Among the sedentary activities, girls spent a daily average of almost four 30-min blocks watching television or movies, more than half a 30-min block playing video games or using the Internet, about 1.530 -min blocks hanging around, and one 
30-min block on home work. Significant differences by race were observed in reporting sedentary activities $(p<.05)$. African American $(p<.01)$ and Asian $(p<.05)$ girls reported significantly more sedentary behaviors on the 3DPAR than Caucasian girls.

\section{Differences by Field Center}

There was a significant difference among the field centers in the number of sedentary hours assessed by accelerometry (see Table 2), with the greatest number in South Carolina (7.9 hr) and lowest in Arizona (7.3 hr; $p<.001)$. The number of hours of light activity also varied among the centers $(p<.001)$; South Carolina had the lowest $(5.3 \mathrm{hr})$ and Minnesota the highest $(5.9 \mathrm{hr})$. The Bonferroni corrected $p$ value was $<.008$ for the analyses reported in Table 2.

The self-report data from the 3DPAR did not reflect these differences among the sites (see Table 3). Statistically significant differences by site were observed only among a few specific activities, such as reported blocks of hanging around and telephone use. In general, there were more blocks of sedentary activities than moderate-to-vigorous physical activities in each field center. Among the sedentary activities in all the field centers, there were more blocks of watching TV/movies, doing homework, and hanging around than other sedentary activities, with California having the most TV/movie watching. Given the analyses reported in Table 3, the Bonferroni corrected standard for significance was $p<.004$.

\section{Sedentary Activity and Overweight/Obesity}

Table 4 presents data on the relationship between sedentary activities and BMI or body fat. Girls whose BMI was between the 85th and 95th percentile $(7.80 \mathrm{hr})$ and those with BMI equal or greater than the 95 th percentile $(7.80 \mathrm{hr})$, as defined by CDC standards (20), had more hours of sedentary activity than those with BMI less than the 85 th percentile ( $7.6 \mathrm{hr} ; p<.01)$. Normal weight and leaner girls had more minutes of moderate-to-vigorous physical activity than overweight or obese girls ( $0.41 \mathrm{hr}$ vs. $0.34 \mathrm{hr}$ at $\geq 4.6 \mathrm{METS})$. While the hours of sedentary activity did not differ during the weekend, girls with BMI $<85$ th percentile had fewer hours of weekday sedentary activity than girls in the other two groups $(p<.001)$. These differences were in hours of sedentary activity both before and after 2:00 p.m. There were no statistically significant differences between the two high BMI groups; however, girls with BMI greater than the 95th percentile had slightly fewer hours of light activity during the weekday and before 2 p.m. The Bonferroni corrected standard for significance was $p<.005$ for the analyses reported in Table 4.

Similar results were noted when percentage of body fat was used to examine the relationship. Girls with more than $35 \%$ body fat had more hours of sedentary activity $(p<.01)$ than girls with less than $30 \%$ body fat. These differences were reflected in weekday activities. Girls with the highest percentage of body fat also had fewer hours of light activity $(p<.05)$ during the weekday and before 2 p.m. Given the analyses reported in Table 4 for percentage of body fat, the Bonferroni corrected standard for significance was $p<.005$.

Table 5 presents the relationships between sedentary activity measured by 3DPAR and BMI or body fat. When classifying girls by BMI category, there were no differences in the number of 30-min activity blocks for any sedentary variable except for time spent snacking $(p<.05)$. A similar finding was noted when classifying girls by percentage $\mathrm{f}$ body fat. The time spent snacking was lowest for girls with $30-34 \%$ body fat and highest for girls with $<30 \%$ body fat $(p<.005)$. Given the analyses reported in Table 5 for BMI and separately for percentage of body fat, the Bonferroni corrected standard for significance was $p<.0042$. 


\section{Discussion}

To our knowledge, this is the first study to use accelerometry to examine sedentary behavior and its relationship to body composition in middle school girls. Our study showed significant associations between body composition and sedentary activity. Obese and overweight girls were more sedentary than normal weight girls. Although the magnitude of difference was small (12-13 min), the findings suggest that even a few minutes of nonsedentary activity could be beneficial (i.e., in preventing excess weight gain). Using the energy expenditure equation from TAAG (Schmidt et al., 2005), we calculated that by replacing 12 min of sedentary time with equivalent minutes of moderate-to-vigorous physical activity, normal weight, at risk of overweight, or overweight girls would spend $17.9,20.2$, and $23.1 \mathrm{kcal} / \mathrm{day}$, respectively or $126-161 \mathrm{kcal} /$ week or a minimum of $4,536 \mathrm{kcal} / 36$ weeks. Assuming 3,500 kcal leads to an average of 1 pound [.45 kg] of weight gain as fat, our results indicated energy expenditure of this magnitude above energy intake could prevent excess weight gain of about 1.3 pounds [ 2.86 $\mathrm{kg}$ ] per year. Wang, Gortmaker, Sobol, and Kuntz, (2006) reported from National Health and Nutrition Examination Survey data that an excess of 110-165 kcal/day is associated with 0.43 $\mathrm{kg}$ ( 0.95 pounds) per year weight gain in 2-7-year-olds. Lifestyle behavioral changes (both diet and physical activity) that include more activity and healthier foods are important for growth and development.

The relationship between body composition and sedentary activity was not evident when physical activity was assessed by self-report (3DPAR) in this study. However, other investigators (Elgar et al., 2005; Robinson et al., 1993; Kettaneh et al., 2005; Maffeis et al., 1998; Gortmaker et al., 1996; Utter et al., 2003) found significant associations when using selfreports. Because this study was cross-sectional, inferences regarding causality cannot be made (i.e., that sedentary behavior causes obesity). However, it is possible that as girls get heavier they become more sedentary, and conversely as girls become more sedentary, they gain more weight. Our findings, as do previous studies (Berkey, Rockett, Gillman, \& Colditz, 2003; Gordon-Larsen et al., 2004), suggest that interventions to decrease sedentary behavior could also prevent pediatric obesity.

Interventions to decrease sedentariness must target all youth, particularly those in regions of the country where girls are mostly sedentary. Such interventions must also encourage walking, hiking, and use of neighborhood facilities and parks that have the potential to enhance physical activity levels. Girls who walk before and after school had 4.7 more minutes of moderate-tovigorous physical activity than those who did not walk (Saksvig et al., 2007). Cohen et al. (2006) noted that girls who lived less than 0.5 miles [0.8 km] away from school had more minutes (14\%) of moderate-to-vigorous physical activity than those who lived 1-5 miles [1.6$8 \mathrm{~km}]$ away.

In general, girls spent about $13 \mathrm{hr}(\sim 97 \%)$ of their waking time in sedentary and light activities. The national recommendation is that youth accumulate at least $60 \mathrm{~min}$ of moderate-to-vigorous physical activity daily. A previous study from TAAG (Pate et al., 2006) reported that few of the girls met national recommendations when the physical activity cut off point was set to 4.6 METs. Interventions to decrease sedentary behavior should emphasize gradual increases in time spent in moderate-to-vigorous physical activity to meet the national recommendations. The finding that sedentary activity time differed across the field centers (range: 12-36 min) may provide guidance for statewide efforts to reduce sedentary activities in middle school girls.

Our study is among the few showing that overweight and obese girls are more sedentary than their normal weight peers. While the reasons for this are numerous, it is plausible that psychosocial factors may explain the higher sedentary behavior in obese girls (De Bourdeaudhuij et al., 2005). Interventions to reduce such behaviors must encourage family/ 
peer support and fun activities that would enhance girls' self-efficacy and interests. Our results suggest that early prevention of overweight and obesity in girls is crucial in reducing the obesity epidemic and the associated comorbidities such as type 2 diabetes and hypertension.

We found nonsignificant relationships between body composition and self-report measures of sedentary behavior. Self-reports using the 3DPAR provide the context and types of daily physical activity that cannot be obtained through accelerometry. Self-reports of children's physical activity, although useful, have limitations, including the potential for socially desirable responses and recall bias. Objective measures of physical activity, although fairly new, should be used to accurately assess sedentary behavior and physical activity in children.

Of the activities examined, girls spent $54-64 \%$ of their sedentary activity watching TV, videos, and movies, using the Internet, and hanging around. This finding suggests that interventions to decrease sedentary behavior must focus on limiting the time spent on these activities. The American Academy of Pediatrics (2001) recommends that parents limit total media time, including children's TV/video viewing and computer use to no more than 1-2 hr daily.

The limitations of this study include its cross-sectional nature. In addition, we did not assess dietary intake, nor did we address the mechanisms associated with sedentary behavior and obesity or the related effects of weather on physical activity. Although physical activity was measured objectively, the activity levels of girls who swam or played competitive sports where accelerometers could not be worn may have been underestimated. Future research should address these shortcomings.

Despite these limitations, the study has many strengths, including being the first to use 6 days of accelerometry data to examine sedentary activity and body composition in a large sample of ethnically and racially diverse girls. It is also one of the few studies to examine, both objectively and by self-report, sedentary activities in girls 12 or more years of age. It substantiates the positive relationship between sedentary behavior and adiposity when measuring physical activity objectively.

\section{Conclusion}

We conclude that sixth-grade girls with higher BMI and percentage of body fat have somewhat greater sedentary behavior than those with BMI $<85$ th percentile or $<30 \%$ body fat. The difference between the high BMI groups and those $<85$ th percentile BMI varied from $1 \%$ to $5 \%$, and from $1 \%$ to $4 \%$ for body fat. Thus, our study documents small but significant association of sedentary activity (measured objectively) with BMI and percentage of body fat. Longitudinal studies are needed to examine the relationship between sedentary behavior and incidence of obesity.

\section{References}

Ainsworth BE, Haskell WL, Whitt MC, Irwin ML, Swartz AM, Strath SJ, et al. Compendium of physical activities: An update of activity codes and MET intensities. Medicine \& Science in Sports \& Exercise 2000;32:S498-S516. [PubMed: 10993420]

American Academy of Pediatrics. Children, adolescents and television. Pediatrics 2001;107:423-426. [PubMed: 11158483]

Berkey CS, Rockett HRH, Gillman MW, Colditz GA. One-year changes in activity and inactivity among 10- to 15-year-old boys and girls: Relationship to change in body mass index. Pediatrics 2003;111:836843. [PubMed: 12671121]

Catellier JD, Hannan PJ, Murray DM, Addy CL, Conway TL, Yang S, et al. Imputation of missing data when measuring physical activity by accelerometry. Medicine \& Science in Sports \& Exercise 2005;37:S555-S562. [PubMed: 16294118] 
Cohen D, Ashwood S, Scott MM, Overton A, Evenson KR, Staten LK, et al. Public parks and physical activity among adolescent girls. Pediatrics 2006;118:el381-e1389.

Daniels SR, Arnett DK, Eckel RH, Gidding SS, Hayman LL, Kumanyika S, et al. Overweight in children and adolescents: Pathophysiology, consequences, prevention, and treatment. Circulation 2005;111:1999-2012. [PubMed: 15837955]

De Bourdeaudhuij I, Lefevre J, Deforche B, Wijndaele K, Matton L, Philippaerts R. Physical activity and psychosocial correlates in normal weight and overweight 11- to 19-year-olds. Obesity Research 2005;13:1097-1105. [PubMed: 15976153]

Elgar FJ, Roberts C, Tudor-Smith C. Sedentary behaviors, physical activity, and weight problems in adolescents in Wales. Public Health 2005;119:518-524. [PubMed: 15826893]

Gordon-Larsen P, Melissa C, Popkin BM. Longitudinal physical activity and sedentary behavior trends: Adolescence to adulthood. American Journal of Preventive Medicine 2004;27:277-283. [PubMed: 15488356]

Gortmaker SL, Must A, Sobol AM, Peterson K, Colditz GA, Dietz WH. Television viewing as a cause of increasing obesity among children in the United States, 1986-1990. Archives of Pediatric and Adolescent Medicine 1996;150:356-362.

Kettaneh A, Oppert JM, Heude B, Deschamps V, Borys JM, Lommez A, et al. Changes in physical activity explain paradoxical relationship between baseline physical activity and adiposity changes in adolescent girls: the FLVSII study. International Journal of Obesity-Related Metabolic Disorder 2005;29:586-593.

Kimm SY, Glynn NW, Kriska AM, Barton BA, Kronsberg SS, Daniels SR, et al. Decline in physical activity in black girls and white girls during adolescence. New England Journal of Medicine 2002;347:709-715. [PubMed: 12213941]

Lohman T, Ring K, Schmitz KH, Treuth MS, Loftin M, Yang S, et al. The associations of body size and composition with physical activity in adolescent girls. Medicine \& Science in Sports \& Exercise 2006;38:1175-1181. [PubMed: 16775560]

Lowry R, Wechsler H, Deborah A, Galuska A, Fulton JE, Kann L. Television viewing and its associations with overweight, sedentary lifestyle, and insufficient consumption of fruits and vegetables among U.S. high school students: Differences by race, ethnicity, and gender. Journal of School Health 2002;72:413-421. [PubMed: 12617028]

Maffeis C, Talamini G, Tato L. Influence of diet, physical activity and parents' obesity on children's adiposity: a four year longitudinal study. International Journal of Obesity-Related Metabolic Disorder 1998;22:758-764.

Marshall SJ, Biddle SJH, Gorely T, Cameron N, Murdey I. Relationships between media use, body fatness and physical activity in children and youth: A meta-analysis. International Journal Obesity 2004;28:1238-1246.

McMurray RG, Ring KB, Treuth MS, Welk GJ, Pate RR, Schmitz KH, et al. Comparison of two approaches to structured physical activity surveys for adolescents. Medicine \& Science in Sports \& Exercise 2004;36:2135-2143. [PubMed: 15570151]

Murray DM, Catellier DJ, Hannan PJ, Treuth MS, Stevens J, Schmitz KH, et al. School-level intraclass correlation for physical activity in adolescent girls. Medicine \& Science in Sports \& Exercise 2004;36:876-892. [PubMed: 15126724]

Must A, Tybor D. J. Physical activity and sedentary behavior: A review of longitudinal studies of weight and adiposity in youth. International Journal of Obesity 2005;29:S84-S96. [PubMed: 16385758]

Nelson MC, Larsen-Gordon P, Adair LS, Popkin BM. Adolescent physical activity and sedentary behavior: Patterning and long-term maintenance. American Journal of Preventive Medicine 2005;28:259-266. [PubMed: 15766613]

Ogden CL, Carroll MD, Curtin LR, McDowell MA, Tabak CJ, Flegal KM. Prevalence of overweight and obesity in the United States, 1999-2004. Journal of the American Medical Association 2006;295:1549-1555. [PubMed: 16595758]

Ogden CL, Kuczmarski RJ, Flegal KM, Mei Z, Guo S, Wei R, et al. Centers for Disease Control and Prevention 2000 growth charts for the United States: Improvements to the 1977 National Center for Health Statistics version. Pediatrics 2002;109:45-60. [PubMed: 11773541] 
Pate RR, Stevens J, Pratt C, Sallis JF, Schmitz KH, Webber LS, et al. Objectively measured physical activity in sixth-grade girls. Archives of Pediatrics and Adolescebt Medicine 2006;160:1262-1268.

Pratt M, Macera CA, Blanton C. Levels of physical activity and inactivity in children and adults in the United States: Current evidence and research issues. Medicine \& Science in Sports \& Exercise 1999;31:526-533.

Robinson TN. Reducing children's television viewing to prevent obesity: A randomized controlled trial. Journal of the American Medical Association 1999;282:1561-1567. [PubMed: 10546696]

Robinson TN. Television viewing and childhood obesity. Pediatric Clinics of North America 2001;48:1017-1025. [PubMed: 11494635]

Robinson TN, Hammer LD, Killen JD, Kraemer HC, Wilson DM, Hayward C, et al. Does television viewing increase obesity and reduce physical activity? Cross-sectional and longitudinal analyses among adolescent girls. Pediatrics 1993;91:273-280. [PubMed: 8424000]

Saksvig B, Catellier D, Pfeiffer D, Schmitz K, Going S, Ward D, et al. Travel by walking before and after school increases physical activity among adolescent girls. Archives of Pediatrics and Adolescent Medicine 2007;161:153-158. [PubMed: 17283300]

Schmidt KH, Treuth M, Hannan P, McMurray R, Ring KB, Catellier D, et al. Predicting energy expenditure from accelerometry counts in adolescent girls. Medicine \& Science in Sports \& Exercise 2005;37:155-161. [PubMed: 15632682]

Stevens J, Murray DM, Catellier DJ, Lytle LA, Elder JP, Young DR, et al. Design of the Trial of Activity for Adolescent Girls (TAAG). Contemporary Clinical Trials 2005;26:223-233. [PubMed: 15837442]

Treuth MS, Schmitz K, Catellier DJ, McMurray RG, Murray DM, Almeida MJ, et al. Defining accelerometer thresholds for physical activity intensities in adolescent girls. Medicine \& Science in Sports \& Exercise 2004;36:1259-1266. [PubMed: 15235335]

Utter J, Sztainer-Neumark D, Jeffery R, Story M. Couch potatoes or French fries: Are sedentary behaviors associated with body mass index, physical activity, and dietary behaviors among adolescents? Journal of the American Dietetic Association 2003;103:1298-1305. [PubMed: 14520247]

Wang YC, Gortmaker SL, Sobol AM, Kuntz KM. Estimating the energy gap among U.S. children: A counterfactual approach. Pediatrics 2006;118:e1721-e1733. [PubMed: 17142497]

Westonn AT, Petosa R, Pate RR. Validation of a three-day physical activity recall instrument in female youth. Medicine \& Science in Sports \& Exercise 1997;29:138-143. [PubMed: 9000167]

\section{Acknowledgments}

This research was funded by grants from the National Heart, Lung, and Blood Institute. Grant numbers: U01HL066858, U01HL066857, U01HL066845, U01HL066856, U01HL066855, U01HL066853, and U01HL066852. The authors thank all the study staff, including project coordinators and measurement staff, the schools, parents, and sixth-grade girls. Please address all correspondence concerning this article to Charlotte A. Pratt, 6701 Rockledge Drive, MSC 7936, Room 10118, Bethesda, MD 20892. 


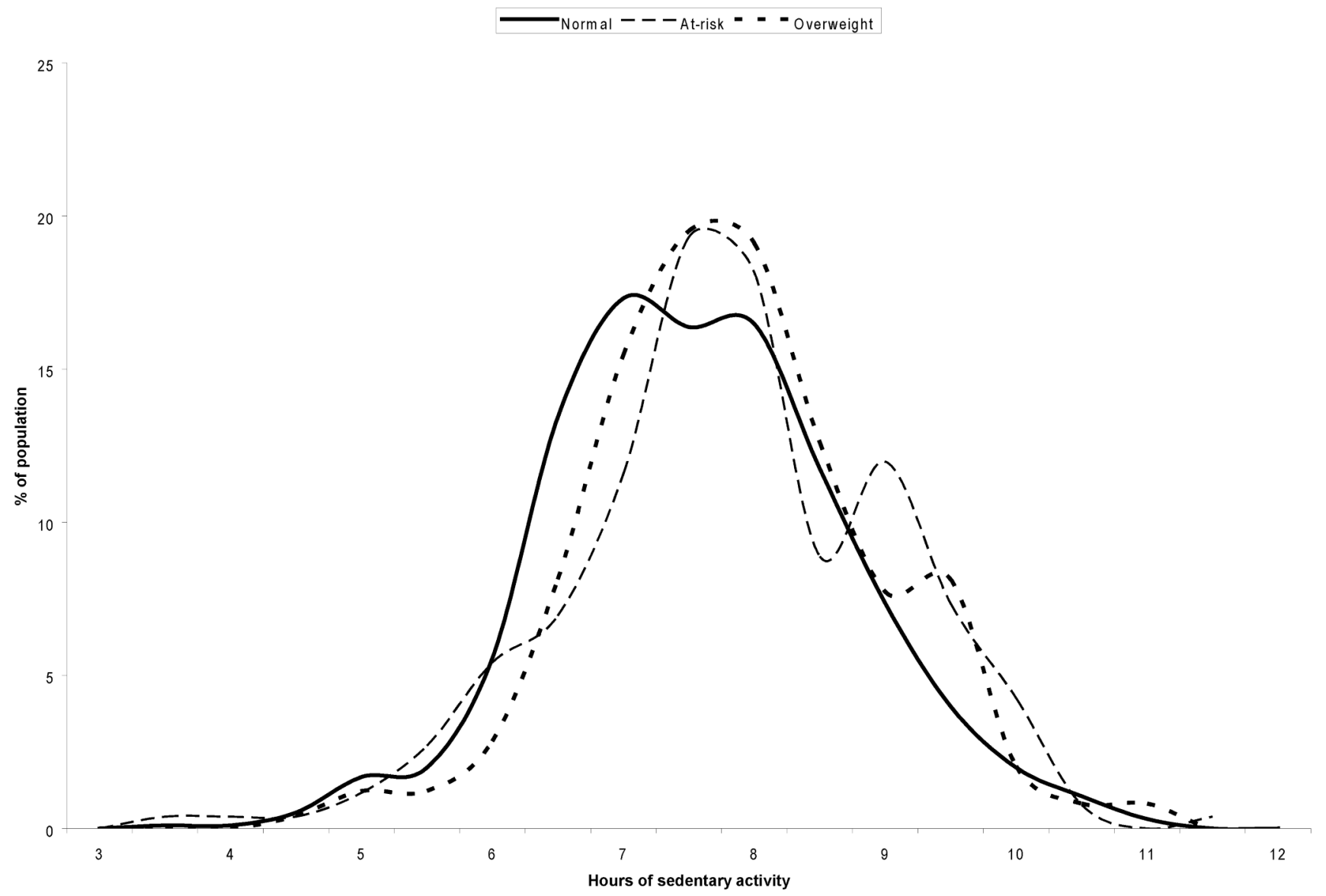

Figure 1.

Hours of sedentary activity by study population. 
Table 1

Characteristics of sixth-grade girls in the trial of activity for adolescent girls

\begin{tabular}{|c|c|c|}
\hline & $M$ & $S D$ or percent \\
\hline Age & 12.0 & 0.5 \\
\hline \multicolumn{3}{|l|}{ Race/ethnicity $\%$} \\
\hline Caucasians & 44.3 & \\
\hline African Americans & 22.0 & \\
\hline Hispanics & 22.0 & \\
\hline Asians & 3.7 & \\
\hline American Indians & 0.8 & \\
\hline Multiracial & 7.5 & \\
\hline Body mass index, $\mathrm{kg} / \mathrm{m}^{2}$ & 21.1 & 4.8 \\
\hline \multicolumn{3}{|l|}{ Body mass index status } \\
\hline$\%$ Not overweight $(<85$ th percentile $)$ & 65.4 & \\
\hline$\%$ At risk of overweight ( 85 th-94.9th percentile) & 17.8 & \\
\hline$\%$ Overweight $(\geq 95$ th percentile $)$ & 16.9 & \\
\hline Mean percentage of body fat & 28.5 & 8.9 \\
\hline \multicolumn{3}{|l|}{ Percentage of body fat } \\
\hline$<30$ & 59.2 & \\
\hline $30-34.9$ & 16.2 & \\
\hline$\geq 35$ & 24.6 & \\
\hline$\%$ Receiving free or reduced lunch & 42.2 & \\
\hline Sedentary hours per day (accelerometry) ${ }^{a}$ & 7.7 & 1.2 \\
\hline$\%$ of total sedentary hours per day & 55.7 & 6.6 \\
\hline Light hours per day (accelerometry) & 5.7 & 1.0 \\
\hline$\%$ of total light hours per day (accelerometry) & 41.4 & 5.9 \\
\hline
\end{tabular}

Note. $M=$ mean; $S D=$ standard deviation.

${ }^{a}$ Sedentary defined as $\leq 50$ accelerometer counts/30 s ( 2.1 metabolic equivalents); light activity as $51-1,499$ counts/30 s ( $<4.6$ metabolic equivalents; Treuth et al., 2004). 
Pratt et al.

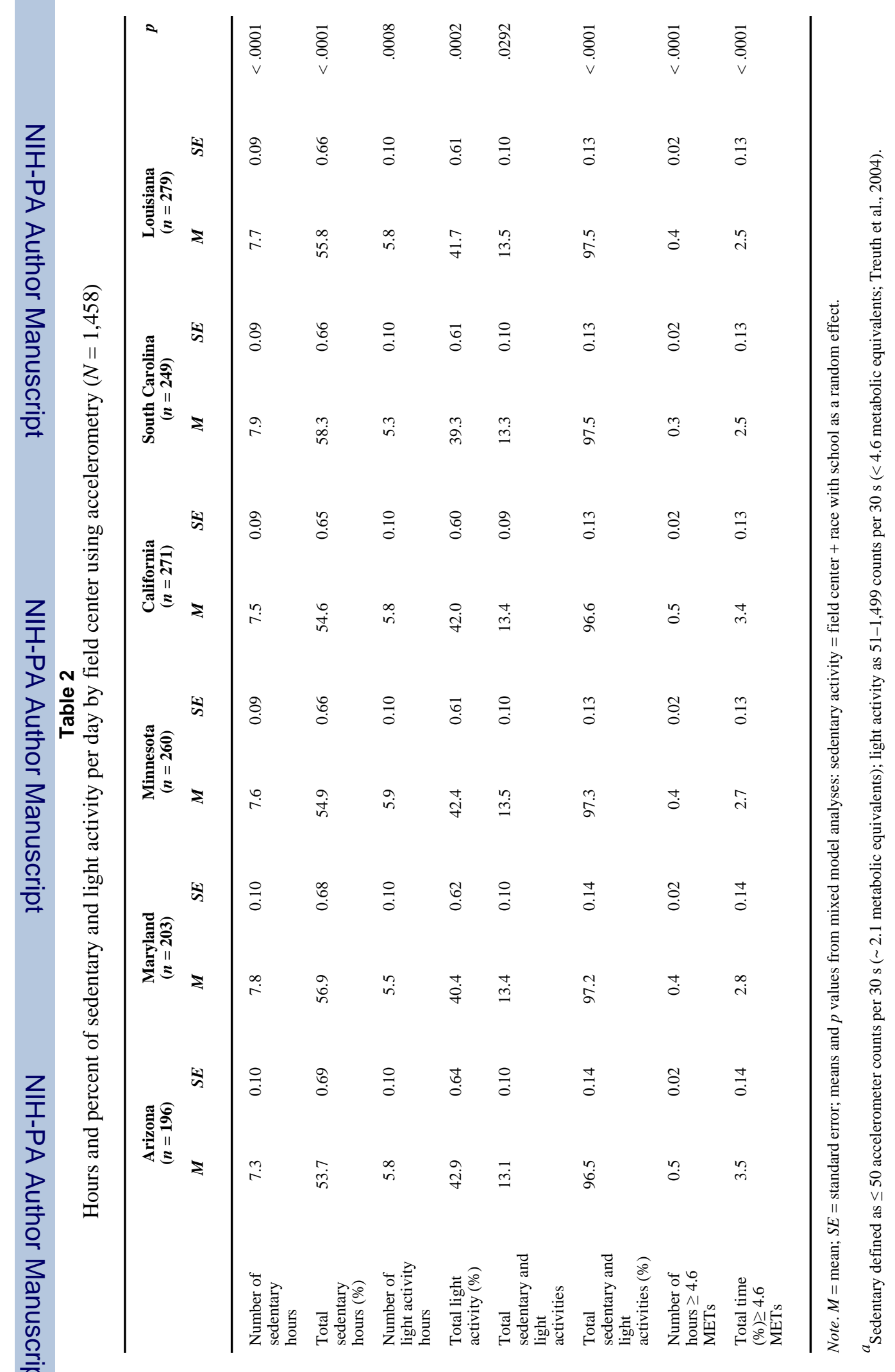

Res Q Exerc Sport. Author manuscript; available in PMC 2009 June 24. 


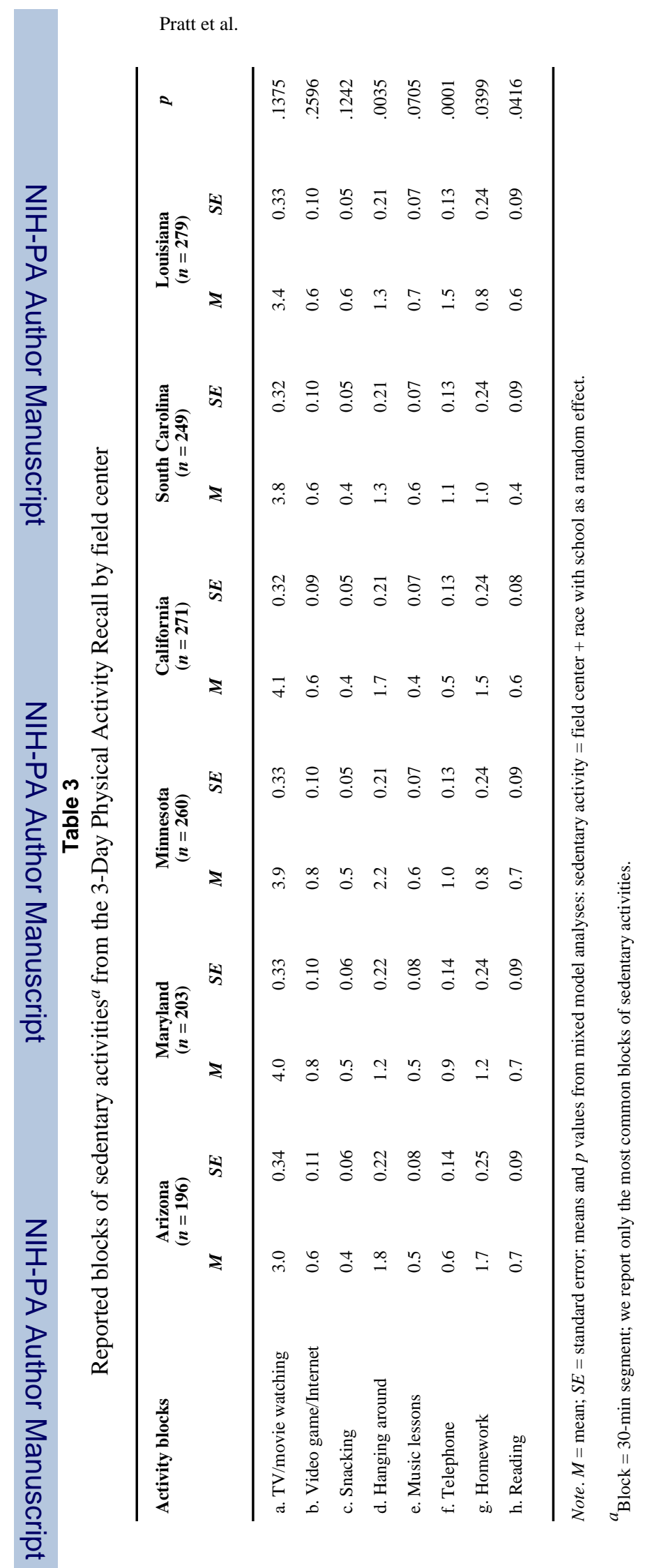

Res Q Exerc Sport. Author manuscript; available in PMC 2009 June 24. 
Pratt et al.

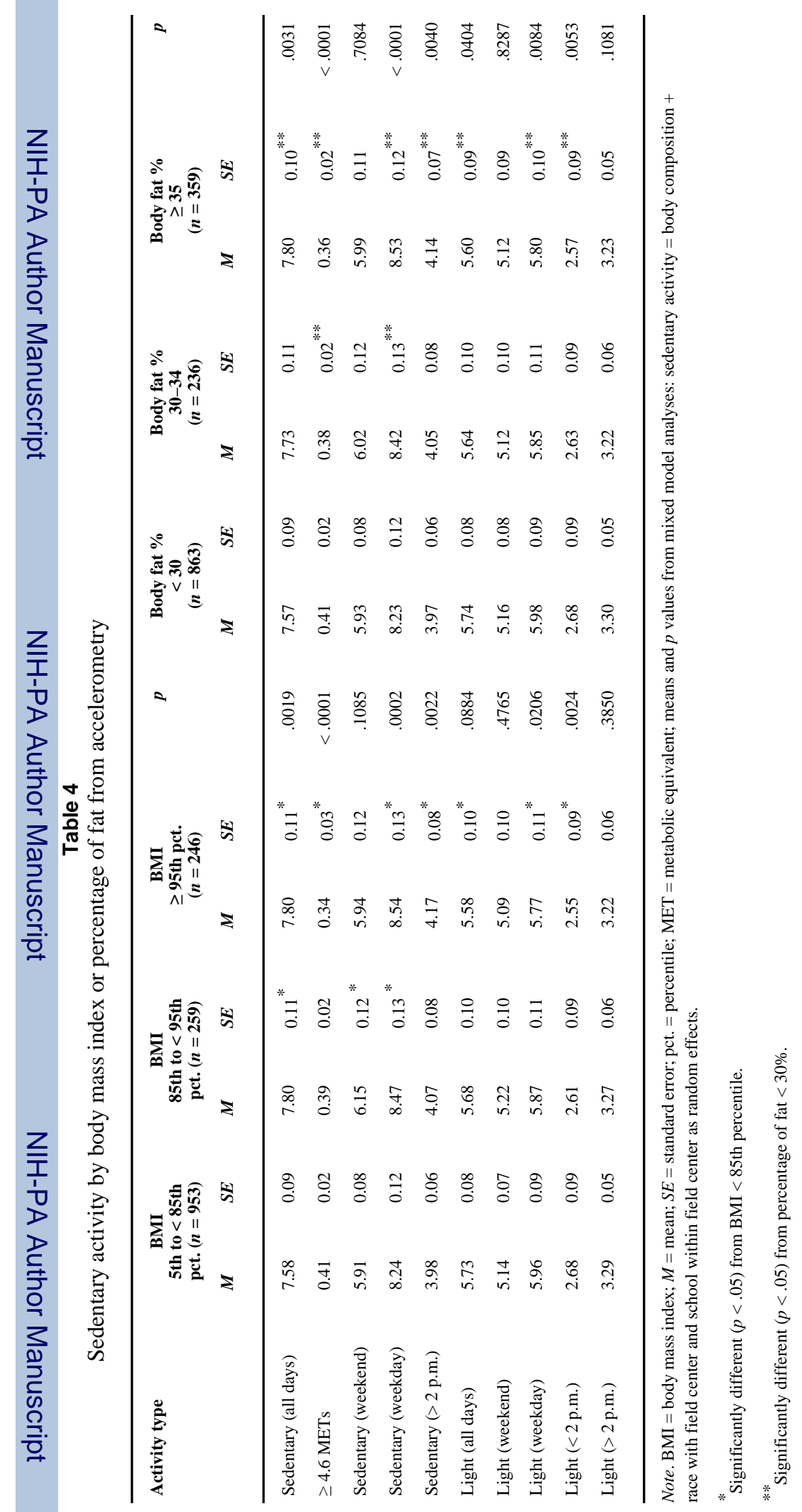

Res Q Exerc Sport. Author manuscript; available in PMC 2009 June 24. 
Pratt et al.

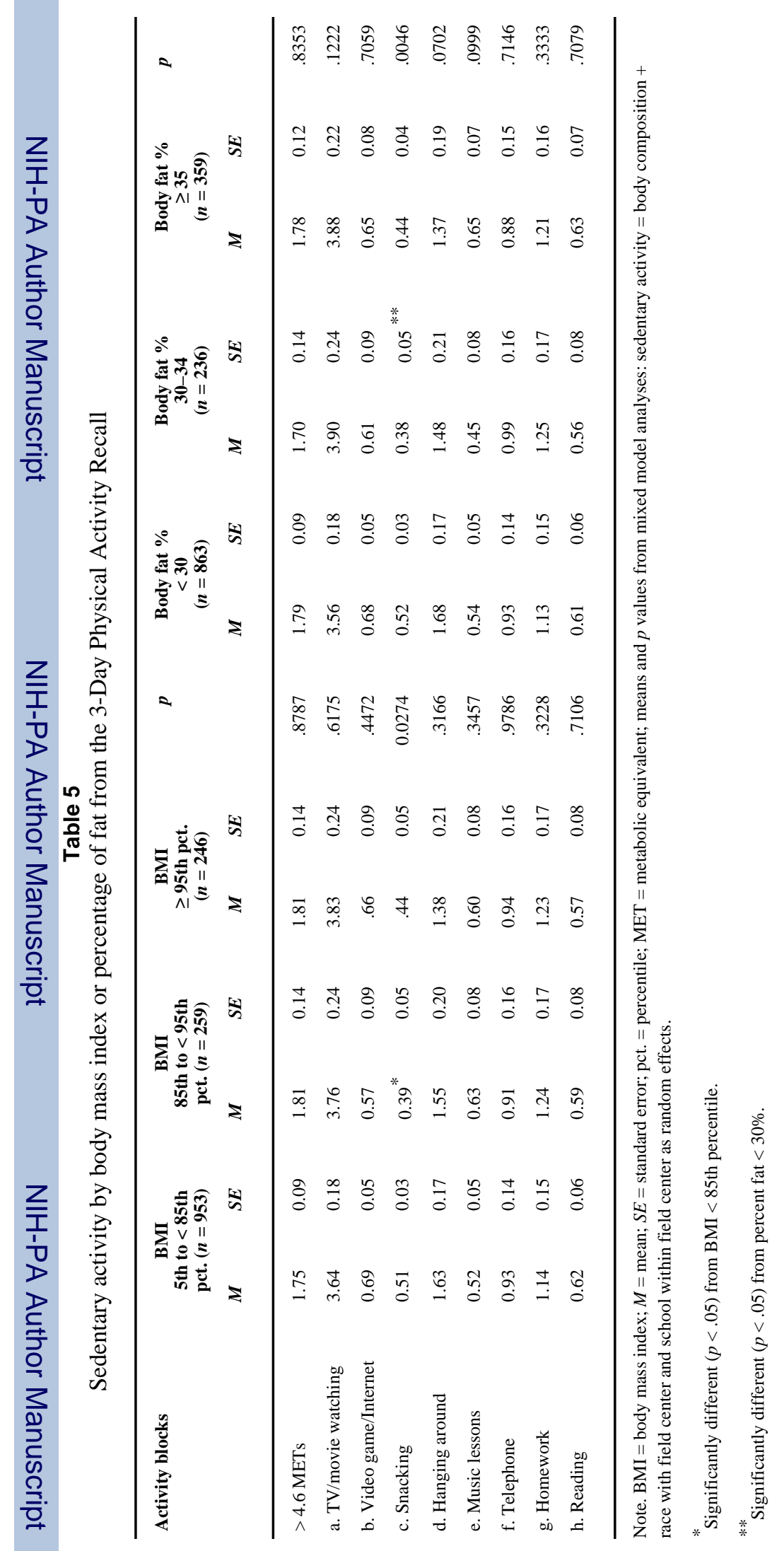

Res Q Exerc Sport. Author manuscript; available in PMC 2009 June 24. 